\title{
Film Formation and Foamability of Cellulose Derivatives: Influence of Co-binders and Substrate Properties on Coating Holdout
}

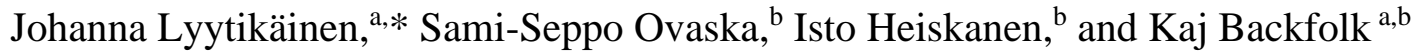

Foams were prepared from hydrophobically modified ethyl(hydroxyethyl) cellulose (EHEC), methyl nanocellulose, and native microfibrillated cellulose (MFC). Their film- and foam-forming abilities, stabilities, and suitabilities for foam coating on different substrates were investigated. The role of EHEC as a polymeric stabilizing agent was also studied. The EHEC-MFC foams showed greater stability and water-holding ability under pressurized dewatering than MFC foams prepared in the presence of a surfactant. A foam could be created with methyl nanocellulose without any foaming agent. Selected nanocellulose gels and foam formulations were used to coat various substrates. The surface was efficiently closed by gel and foam coatings prepared from the methyl nanocellulose and EHEC solutions, which was ascribed to good coating holdout. Coatings on papers with different levels of smoothness/density and hydrophobicity/ hydrophilicity confirmed that foam-substrate interactions affected the coat quality. The air permeance was reduced by $99 \%$ and $64 \%$ with a methyl nanocellulose coating and an EHEC-MFC coating, respectively. An EHEC-MFC coating created a hydrophobic surface on a hydrophilic substrate, and methyl nanocellulose improved the oil resistance even at a low coat weight.
\end{abstract}

Keywords: Coating; Film-formation; Foam; Hydrophobically modified EHEC; Methyl nanocellulose; $M F C$

Contact information: a: School of Energy Systems, Lappeenranta-Lahti University of Technology LUT, P. O. Box 20, FI-53851 Lappeenranta, Finland; b: Stora Enso Oyj, FI-55800 Imatra, Finland;

*Corresponding author: Johanna.Lyytikainen@lut.fi

\section{INTRODUCTION}

Surface treatment of paper and paperboard substrates is essential to achieve barrier and functional properties in packaging materials. Polymer solutions or dispersions for making barrier coatings must have good film-forming ability and be suitable for use in high-speed on-line or off-line coating processes. To solve some of the existing challenges, new processes and concepts must be identified and developed.

Microfibrillated cellulose (MFC) or nanocellulose can provide good oil and grease resistance and can be a good oxygen barrier if the coat weight and thickness are sufficient (Aulin et al. 2010; Lavoine et al. 2014; Kumar et al. 2016, Yook et al. 2020). Unfortunately, in traditional coating processes, the rheological characteristics of MFC cause problems associated with its gel behavior at low solids contents. Also, with a low solids content, a wet coating is difficult to dry rapidly, and this interferes with film formation.

Foam coating enables high-viscosity coating paste to be applied, and foam coating has recently been used to apply thin coating layers (Kenttä et al. 2014; Kinnunen- 
Raudaskoski et al. 2014; Kenttä et al. 2016; Kinnunen-Raudaskoski et al. 2017). In this coating method, the coating component is located within the bubble matrix. The foam is generated by mixing the coating paste with pressurized air in a foam generator. The air content of the foam has been reported to be at least $80 \%$ in foam coating, and this is referred to as dry foam (Kinnunen-Raudaskoski et al. 2014). Foam with small bubbles and a narrow bubble size distribution provides a uniform coating (Kinnunen-Raudaskoski et al. 2014). Foam coating has been used with high-viscosity cellulose nanofibrils, for example, native, (2,2,6,6-tetramethylpiperidin-1-yl)oxyl (TEMPO)-oxidized, and functionalized cellulose nanofibrils have been used for foam coating to create thin coatings, but in these cases, surfactants were used to aid the foam formation (Kinnunen-Raudaskoski et al. 2014, 2017).

Amphiphilic surfactants are usually used to create and stabilize the foams. Particles or polymeric surfactants can be used to stabilize emulsions (called Pickering emulsions), but Pickering stabilization can also be used to stabilize an air-water interface to create a highly stable foam (Cervin et al. 2013; Lam et al. 2014). In Pickering stabilization, partially hydrophobic particles are used to attach to the air-water interface, while relatively hydrophilic particles adsorb onto the oil-water interface (Cervin et al. 2013; Lam et al. 2014, Bertsch et al. 2019). The particles attached to the air-water interface resist the growth or shrinkage of the bubbles, and such particle-stabilized foams have the potential to be more stable than surfactant-stabilized foams (Hunter et al. 2008; Cervin et al. 2013; Fujisawa et al. 2017). In addition, the poor biodegradation of many surfactants has driven the development of surfactant-free systems and the use of bio-based and biodegradable alternatives (Lam et al. 2014; Fujisawa et al. 2017; Gong et al. 2017).

Cellulose particles have been used to increase the stability of aqueous foams. Cellulose nanofibrils (CNF) have been used as Pickering stabilizers in foams where octylamine has been adsorbed onto the surface of TEMPO-oxidized CNF (Cervin et al. 2016). In addition, octylamine and decylamine have been adsorbed onto the surfaces of native CNF to increase foam stability (Cervin et al. 2013, 2015). Unmodified cellulose nanocrystals $(\mathrm{CNC})$ have been adsorbed onto an air-water interface to create Pickeringstabilized foams (Bertsch et al. 2018). The stability of pulp foams was increased with MFC in the presence of surfactant and retention aid (Liu et al. 2018).

The effects of surfactants on the barrier properties of biopolymer films and coatings have been studied to some extent. For example, non-ionic, oil-soluble surfactants were found to increase the water vapor barrier properties of corn starch-glycerol films and hydroxypropyl methylcellulose coatings (Villalobos et al. 2006; Villalobos-Carvajal et al. 2009; Ortega-Toro et al. 2014). The adsorption of cationic surfactant on TEMPO-mediated oxidized nanofibrils increases the hydrophobicity and reduces the wettability of the films (Xhanari et al. 2011), but the oxygen permeability of corn starch-glycerol films increased when surfactant was added (Ortega-Toro et al. 2014). The increase in oxygen permeability has been attributed to the lower polarity of the material, which also indicates poorer oil and grease resistance (Miller and Krochta 1997; Hubbe et al. 2017).

Cellulose derivatives such as ethyl(hydroxyethyl)cellulose (EHEC) and methyl cellulose produce foams when the surface tensions of the aqueous solutions are reduced (Poptoshev et al. 1997; Hu et al. 2016). Cellulose nanocrystals alone do not decrease the surface tension and thus do not produce foams, but the stability of methyl cellulose foams can be increased with CNC (Hu et al. 2016). Wemmer et al. (2019) used methyl cellulose as a foaming agent when studying the effect of replacing MFC with methyl cellulose on the mechanical properties and structure of the foam. 
This study investigated the foamabilities and stabilities of foams containing hydrophobically modified EHEC, methylated nanocellulose, and native MFC, along with the importance of the dosing sequence and preparation methods. Different base substrates were designed and prepared to clarify the effects of substrate hydrophobicity and roughness on foam wetting, foam spreading, foam stability, and absorption properties.

\section{EXPERIMENTAL}

\section{Materials and Methods}

Solutions with different proportions of MFC (Celish KY100S, Daicel, Osaka, Japan), hydrophobically modified EHEC (Bermocoll EHM 200, Akzo Nobel Functional Chemicals AB, Kumla, Sweden), and methyl nanocellulose (MeCellosic acid, MCA, Innotech Materials, Wauwatosa, WI, USA) at different concentrations were prepared, together with foams containing MFC and sodium dodecyl sulfate (SDS) solutions (Merck KGaA, Darmstadt, Germany) at $1 \mathrm{wt} \%, 2 \mathrm{wt} \%$, and $3 \mathrm{wt} \%$ concentrations. Anionic SDS was added as a foaming agent with an addition of $0.2 \%$ of the liquid volume. Foams were generated with a Rollmix BGR 13 foam generator (Rollmac, Trissino, Italy).

The rheological behaviors of the non-foamed solutions were determined with a modular compact rheometer (MCR 302, Anton Paar, Graz, Austria) using the CC27 measurement cylinder. The viscosities were measured at different shear rates in the range of $0.1 \mathrm{~s}^{-1}$ to $1000 \mathrm{~s}^{-1}$ and at a shear rate of $50 \mathrm{~s}^{-1}$ with the solution heated from $20{ }^{\circ} \mathrm{C}$ to 70 ${ }^{\circ} \mathrm{C}$. The heating rate was $0.5^{\circ} \mathrm{C} / \mathrm{min}$.

The foam density was assessed by collecting and weighing foam in a $100-\mathrm{mL}$ measuring cylinder. The viscosity of the foam was measured with a digital viscometer (Model DV-II+, Brookfield Engineering Laboratories, Inc., Middleboro, MA, USA) using spindle \#6 at speeds of $10 \mathrm{rpm}$ and $50 \mathrm{rpm}$. Foam stability was assessed by studying the collapse of the foam. Foam was collected in a $100-\mathrm{mL}$ measuring cylinder, avoiding any air gaps in the sample. The degree of collapse of the foam and the volume of liquid were recorded for $60 \mathrm{~min}$.

The gravimetric water retention of the foams was measured by the Åbo Akademi gravimetric water retention ( $\AA$ AGWR) method, in which $10 \mathrm{~mL}$ of foam was placed in a sample cylinder. Cellulose chromatographic paper (Whatman Grade Chr 17, Cytiva, Buckinghamshire, UK) was used as absorbing paper, and the transferred amount of liquid was reported as the average of three parallel measurements.

The foam coatings were made on uncalendered and calendered hydrophilic and hydrophobic substrates with a desktop rod coater using a rod with a wire diameter of 0.2 $\mathrm{mm}$ (Venema rod coater, Lorentzen \& Wettre, Stockholm, Sweden). The grammage of all the base substrates was $100 \mathrm{~g} / \mathrm{m}^{2}$, and a calender nip pressure of $60 \mathrm{kN} / \mathrm{m}$ was used for calendering. Samples were coated three times and dried at $105{ }^{\circ} \mathrm{C}$ after each coating layer.

The coated samples were conditioned at $23{ }^{\circ} \mathrm{C}$ and $50 \%$ relative humidity before testing. Air permeability was measured using an L\&W Bendtsen tester (Code 114, AB Lorentzen \& Wettre, Stockholm, Sweden) according to the SCAN-P 85:02 (2002) method. Oil and grease resistance of the coated samples was measured according to the ISO 165321 (2008) standard. Contact angles were measured using an Attension Theta optical tensiometer (Biolin Scientific, Gothenburg, Sweden); deionized water and rapeseed oil were used as test liquids with drop volumes of 3 and $5 \mu \mathrm{L}$, respectively. 
A scanning electron microscope (SEM) (Hitachi SU3500, Tokyo, Japan) with a secondary electron detector and tungsten filament was used to capture micrographs of the samples. Before imaging, the coated sides of the samples were sputter-coated with gold. The acceleration voltage was $10 \mathrm{kV}$, and the working distance was approximately $5 \mathrm{~mm}$.

\section{RESULTS AND DISCUSSION}

\section{Rheological Characterization of the Non-foamed Solutions}

Figure 1 shows the effects of temperature on the viscosities of the different solutions. With increasing temperature, the viscosity decreased for the $1 \mathrm{wt} \% \mathrm{MFC}$ solution and especially for the $1 \mathrm{wt} \%$ EHEC solution (Fig. 1A), although the thermoresponsive behavior of the latter was due to hydrophobic association and phase separation (Thuresson and Lindman 1997). The methyl nanocellulose solution's viscosity increased with increasing temperature. Gelation at an increased temperature is characteristic of methylcellulose, and it has been suggested that this behavior is due to interactions among hydrophobic groups in the polymer (Desbrières et al. 2000; Fairclough et al. 2012; Arvidson et al. 2013). Hydrophobically modified EHEC associates similarly via hydrophobic groups, but the association is weak and breaks easily under shear, as shown by the decrease in viscosity.

The blends of native MFC and EHEC exhibited decreasing viscosity with increasing temperature (Fig. 1B). The $1 \mathrm{wt} \%$ mixture showed a slightly lower viscosity than MFC, although the addition of EHEC would be expected to increase the viscosity based on the viscosity curves in Fig. 1A. The viscosity behaviors of the $1 \mathrm{wt} \%$ and $2 \mathrm{wt} \%$ solutions were similar over the measured temperature range. For the $3 \mathrm{wt} \%$ solution, the viscosity decreased when the heating started and remained almost unchanged between 35 ${ }^{\circ} \mathrm{C}$ and $45^{\circ} \mathrm{C}$, which could be ascribed to the interaction between the nanocellulose and the EHEC polymers (Lyytikäinen et al. 2020).
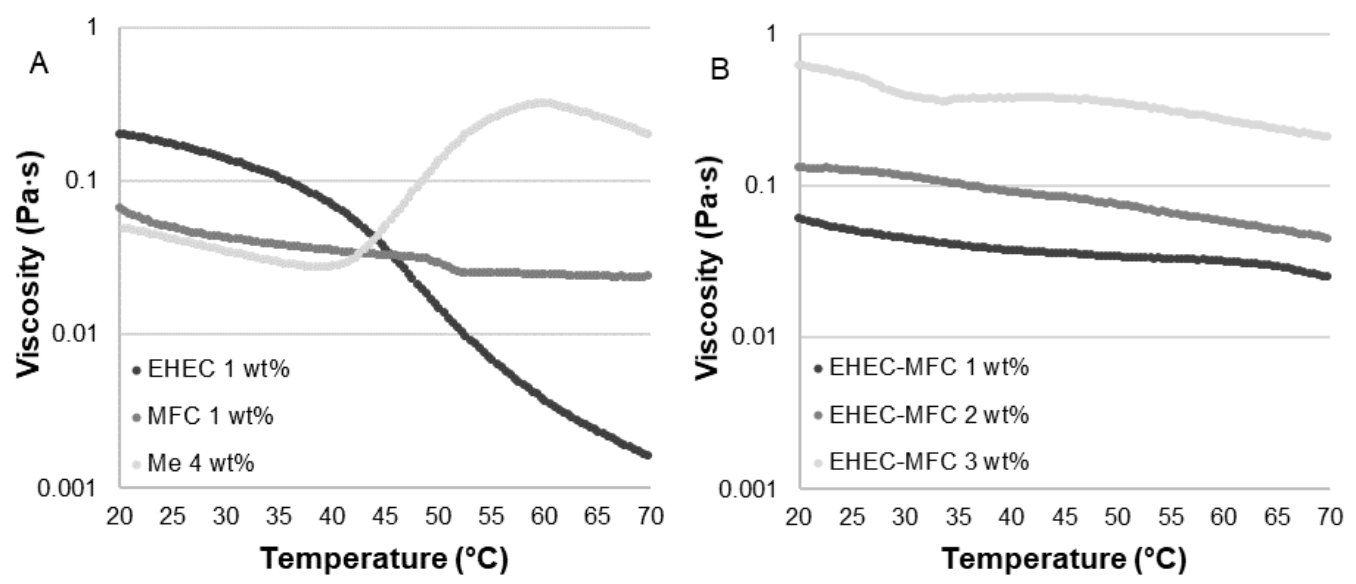

Fig. 1. Viscosities of the EHEC, methyl nanocellulose (Me), MFC, and EHEC-MFC mixtures in a ratio of 25:75 at different temperatures

Figure 2 shows the viscosities at different shear rates. Both the EHEC and MFC solutions showed shear-thinning behavior (Fig. 2A). In the EHEC solution, the low shear rate did not influence the polymeric network, but shear rates greater than $5 \mathrm{~s}^{-1}$ were 
sufficient to break down the polymer network, and the viscosity decreased with increasing shear rate. For the $1 \mathrm{wt} \%$ MFC solution, an increase in viscosity was observed at a shear rate of $10 \mathrm{~s}^{-1}$, which is common, especially for native and non-derivatized MFC suspensions (Iotti et al. 2011; Karppinen et al. 2012; Hiltunen et al. 2018). The viscosity reduction with increasing shear is associated with an orientation of the fibrils, whereas at certain shear rates, the floc size and size distribution increase and fibril-free voids occur which can contribute to a viscosity peak at a given shear rate (Iotti et al. 2011; Karppinen et al. 2012). Methyl nanocellulose showed Newtonian behavior, as the shear rate did not affect the viscosity, but at very low shear rates small changes were seen.

Figure 2B shows the viscosities of the EHEC-MFC solutions as a function of the shear rate. All the solutions were shear thinning. In a $1 \mathrm{wt} \%$ solution, the viscosity increased at a shear rate between 1 and $5 \mathrm{~s}^{-1}$, as was also observed for the pure MFC solution at a greater shear rate. With increasing solids content, the viscosity peak disappeared, as was also seen for MFC suspensions (Iotti et al. 2011). The addition of CMC has a similar effect on the viscosity of MFC, suggesting a reduced tendency to form flocs (Kumar et al. 2017a). The increase in viscosity was notable when the solids content of the solution was increased from $1 \mathrm{wt} \%$ to $3 \mathrm{wt} \%$. The structure becomes more rigid, and this can affect interparticle interaction, which may increase the viscosity at certain shear rates due to formation of flocs and aggregates.
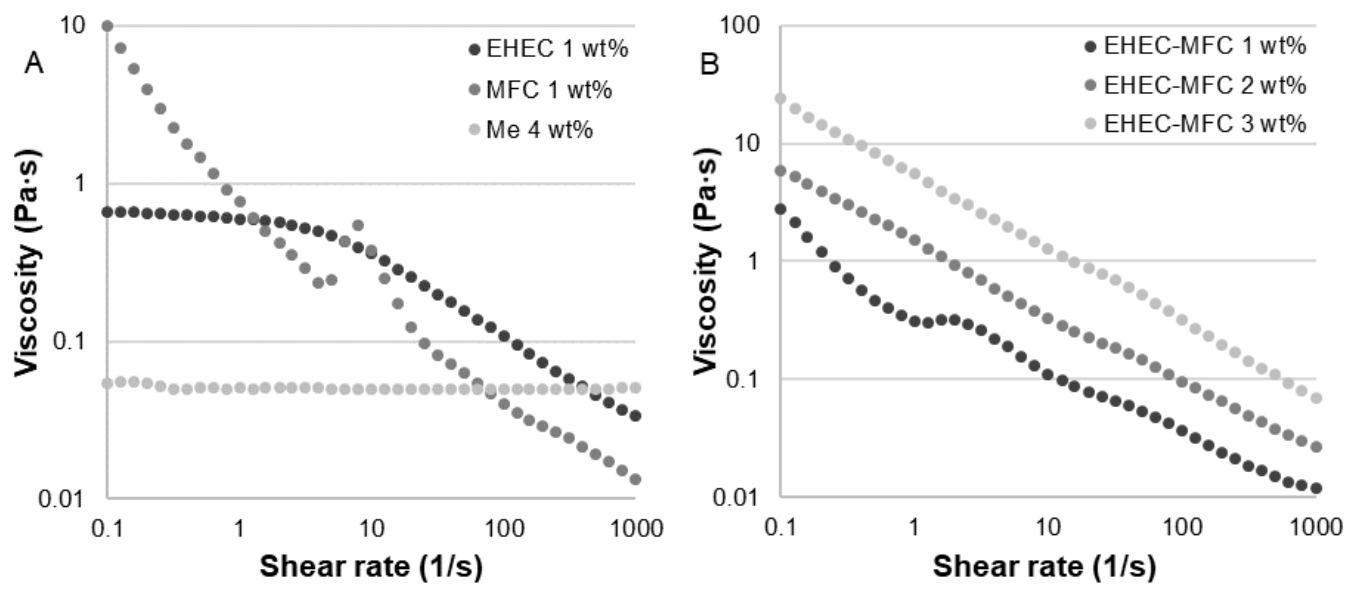

Fig. 2. Viscosity of the EHEC, MFC, methyl nanocellulose (Me), and EHEC-MFC mixtures in a ratio of 25:75 at different shear rates

\section{Foam Formation and Stability}

The MFC-SDS, EHEC-MFC, and EHEC-methylated nanocellulose solutions were foamed with a foam generator. Table 1 shows the main features of the foams: air content, solids content, water release under pressure (AAGWR), and the viscosity determined at two shear rates. The air content of the foam is related to the foam density, and foams with a density greater than $20 \mathrm{~g} / 100 \mathrm{~mL}$ are referred to as wet foams. The foam density was lowest in the MFC-SDS foams and did not notably change when the solids content was increased. For the EHEC-MFC foams, density was greatest when the foam was generated at $3 \mathrm{wt} \%$ of EHEC-MFC and showed a clear concentration dependence. In addition, a greater amount of air bubbles (i.e., a greater amount of air) in the foam reduces the density. The bubble size and the size distribution were evaluated visually and were observed to be lowest in the EHEC-MFC foams and greatest in the methyl nanocellulose foam. The increase in viscosity of the EHEC-MFC foams was attributed to the smaller air bubbles in 
the foam and the increased solids content, especially with the highly viscous MFC. Weak hydrogen bonding between the fibrils results in a less stable foam and also affects the viscosity of the foam (Li et al. 2019).

The water retention values of the foams were determined gravimetrically to understand the foams' abilities to collapse under light pressure and to release water from the collapsed structure. The methyl nanocellulose foam showed the greatest tendency to collapse, whereas the EHEC-MFC foams, especially at greater concentrations, remained almost unchanged. The lower amount of liquid transferred from the EHEC-MFC foams was due to the greater proportion of MFC in the foam, as MFC has a high water-holding capacity, which increases with increasing MFC concentration (Kumar et al. 2017a). In general, the amount of liquid transferred from the MFC-SDS foams was greater than from the EHEC-MFC foams, which was ascribed to the EHEC acting as a water retention agent and thickener of the liquid phase. The EHEC-methyl nanocellulose and pure methyl nanocellulose foams had relatively low water-holding capacities, so more water was transferred to the substrate than from the MFC-containing foams. Comparing the foams generated from the $1 \mathrm{wt} \%$ and $4 \mathrm{wt} \%$ solutions, it was clear that the methyl nanocellulose released more water under the applied pressure. The large amount of transferred liquid and the lower viscosity at a speed of $50 \mathrm{rpm}$ thus confirmed that the methyl nanocellulose foam broke more easily under the applied pressure, and more water was released from the structure. The solids content of the foams containing methyl nanocellulose was however close to that of the solution before foaming, indicating that the material was homogeneously distributed in the foam together with the liquid phase.

Table 1. Foam Properties of MFC-SDS, EHEC-MFC, EHEC-Methyl Nanocellulose, and Methyl Nanocellulose Foams.

\begin{tabular}{|c|c|c|c|c|c|c|}
\hline & $\begin{array}{c}\mathrm{pH} \\
\text { Non-Foamed } \\
\text { Solution }\end{array}$ & $\begin{array}{c}\text { Solids } \\
\text { Content } \\
\text { (\%) }\end{array}$ & $\begin{array}{l}\text { Density } \\
\text { (g/ } 100 \mathrm{~mL})\end{array}$ & $\begin{array}{c}\text { ÅAGWR } \\
\left(\mathrm{g} / \mathrm{m}^{2}\right)\end{array}$ & $\begin{array}{c}\text { Viscosity } \\
(10 \text { rpm) (cP) }\end{array}$ & $\begin{array}{c}\text { Viscosity } \\
\text { (50 rpm) (cP) }\end{array}$ \\
\hline & \multicolumn{6}{|c|}{ MFC-SDS } \\
\hline $1 \mathrm{wt} \%$ & 6.8 & 0.78 & 20.8 & 2230 & 1240 & 552 \\
\hline $2 \mathrm{wt} \%$ & 7.1 & 1.22 & 19.9 & 2257 & 1920 & 752 \\
\hline \multirow[t]{2}{*}{$3 \mathrm{wt} \%$} & 8.3 & 2.08 & 21.9 & 1503 & 1960 & 914 \\
\hline & \multicolumn{6}{|c|}{ EHEC (25\%) : MFC (75\%) } \\
\hline $1 \mathrm{wt} \%$ & 6.0 & 0.94 & 25.4 & 1267 & 1960 & 680 \\
\hline $2 \mathrm{wt} \%$ & 6.3 & 1.85 & 22.9 & 550 & 4860 & 1632 \\
\hline \multirow[t]{2}{*}{3 wt\% } & 6.7 & 2.46 & 45.0 & 289 & 9280 & 3488 \\
\hline & \multicolumn{6}{|c|}{ EHEC (25\%) : Methyl Nanocellulose (75\%) } \\
\hline $3 w t \%$ & 4.1 & 2.93 & 40.4 & 2953 & 3040 & 1640 \\
\hline & \multicolumn{6}{|c|}{ Methyl Nanocellulose } \\
\hline $4 \mathrm{wt} \%$ & 2.9 & 4.01 & 39.1 & 3884 & 3360 & 1500 \\
\hline
\end{tabular}

Figure 3 shows the foam stability after $60 \mathrm{~min}$. The MFC-SDS (Fig. 3A to 3C) foams were less stable than the EHEC-MFC foams (Fig. 3D to 3F), and the stability was only slightly improved when the solids content was increased. This result could be explained by an increasing amount of MFC located between the bubbles and thus a greater water holding capacity and reduced drainage (Xiang et al. 2019), which was also indicated by the gravimetric water retention data. The foam collapsed more with increasing MFC solids content in the MFC-SDS foams, which may indicate an inadequate amount of SDS, as foam stability decreases with decreasing addition of SDS (Lappalainen et al. 2014; 
Xiang et al. 2019). Although the $3 \mathrm{wt} \%$ EHEC-MFC foam could be considered a wet foam, it did not break during the measured time period. The EHEC-MFC $1 \mathrm{wt} \%$ and EHECmethyl nanocellulose foams exhibited similar foam stability, but the EHEC-methyl nanocellulose foam did not show any tendency to collapse (Fig. 3G).

The pure methyl nanocellulose foam (Fig. 3H) was the least stable foam, probably because the larger bubbles and greater size distribution reduced the stability of the foam (Kinnunen-Raudaskoski et al. 2014). The density of the methyl nanocellulose foam was approximately $39 \mathrm{~g} / 100 \mathrm{~mL}$, and the amount of released liquid from the foam was $30 \mathrm{~mL}$. The viscosity data and the gravimetric water retention values of the foams also indicated a low stability (Table 1).

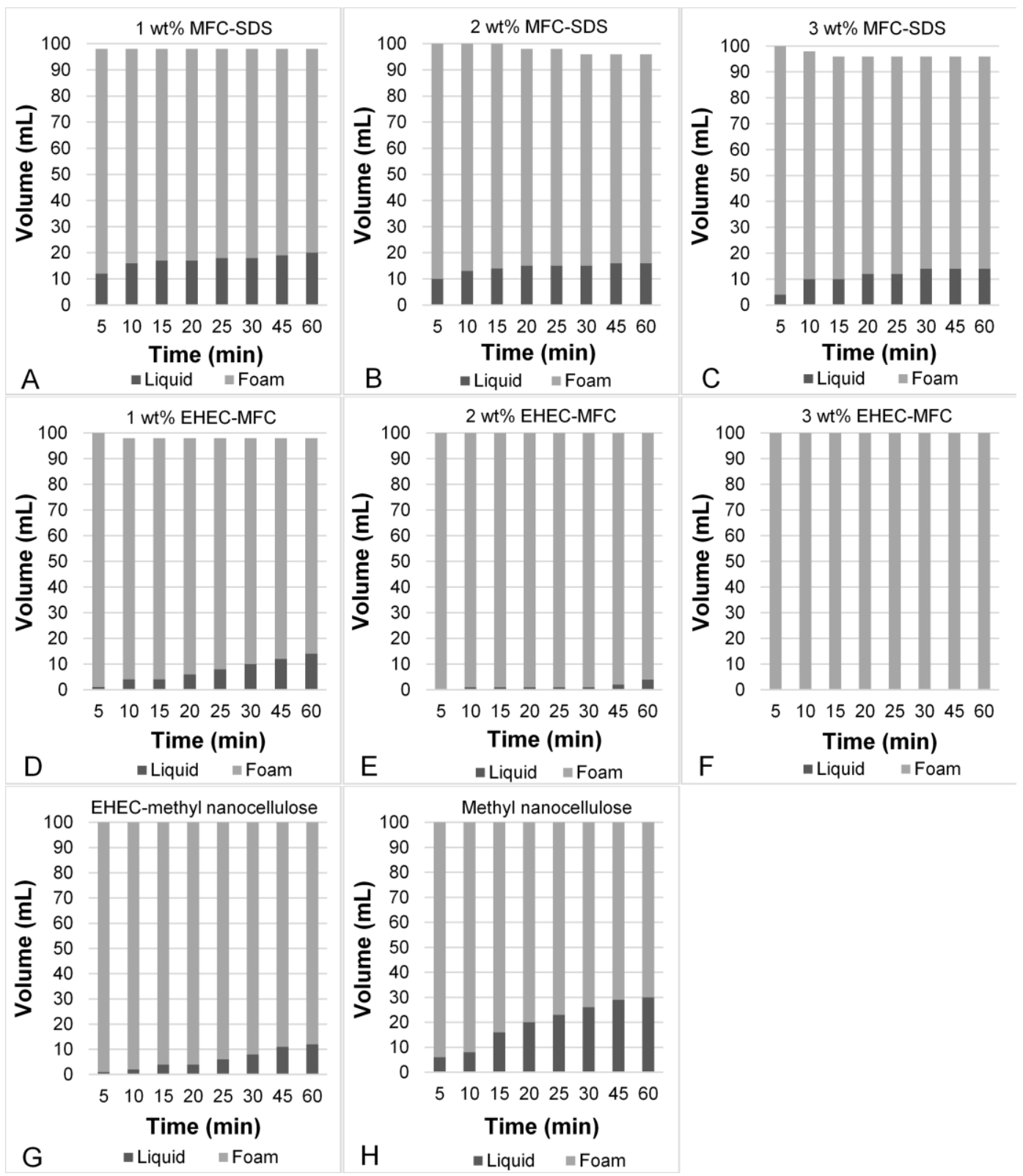

Fig. 3. Stabilities of (A) 1 wt \%, (B) 2 wt $\%$, and (C) 3 wt $\%$ MFC-SDS foams; (D) 1 wt $\%$, (E) 2 wt $\%$, and (F) 3 wt\% EHEC-MFC foams; (G) 3 wt\% EHEC-methyl nanocellulose foam in a ratio of 25:75; and $(\mathrm{H}) 4 \mathrm{wt} \%$ methyl nanocellulose foam presented as amounts of foam which have separated into foam and liquid after different times 


\section{Foam Coating: Effects of Polymeric Additive, Substrate Roughness, and Hydrophobicity}

To evaluate the suitability of foam for coating, $1 \mathrm{wt} \%$ solutions consisting of EHEC and methyl nanocellulose were prepared. An internally sized, uncoated paperboard was coated with a non-foamed solution and with foam. Air permeance values and coat weights were determined from a thrice coated substrate (Fig. 4). The air permeance of the uncoated material was $580 \mathrm{~mL} / \mathrm{min}$.

With both non-foamed solutions and foam, the air permeance first decreased with increasing amounts of methyl nanocellulose, but it increased when the amount of methyl nanocellulose was further increased. With pure EHEC or methyl nanocellulose foams, the air permeance was lower than that of the coating with the non-foamed solution. The lowest air permeance was achieved with a coating containing $25 \%$ or $50 \%$ of methyl nanocellulose, with which the air permeance was reduced by $86 \%$. In these cases, the coat weight was lowest, and there was no great difference in air permeance between the foam and non-foamed coatings. These two foams had the lowest densities, which may indicate that a uniform coating can be achieved with foam with small bubbles even at a low coat weight.

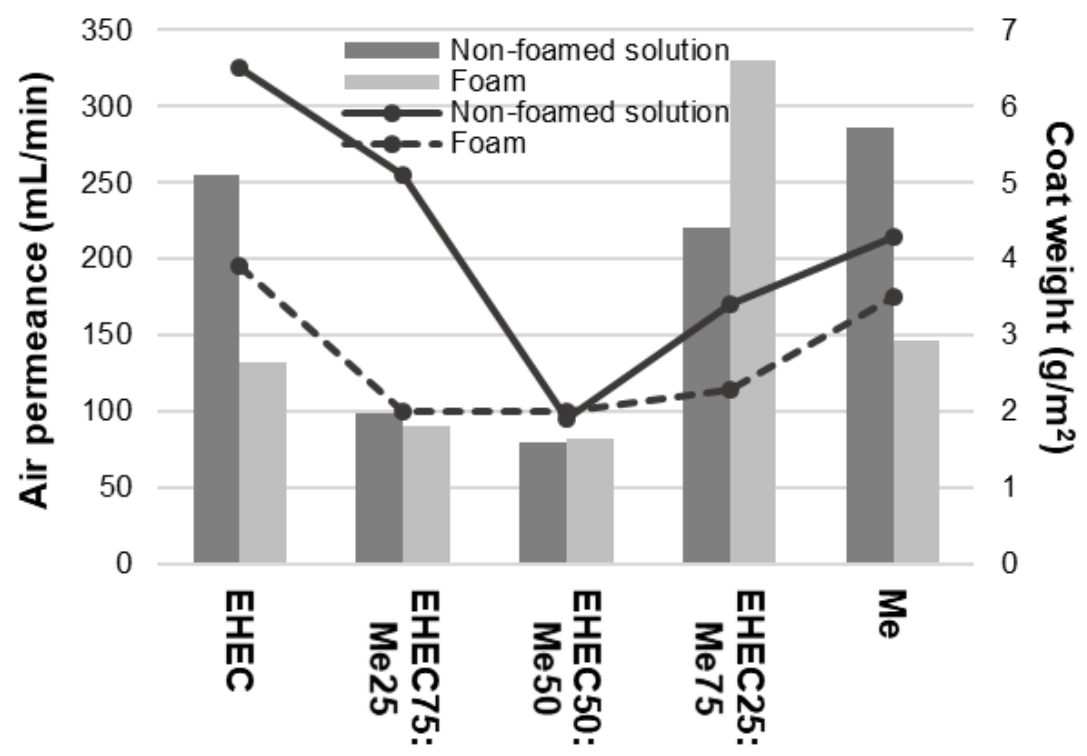

Fig. 4. Coat weight and air permeance values of coated paperboards with non-foamed solutions and foam consisting of EHEC and methyl nanocellulose (Me). The columns show air permeance, and the curves show the coat weight.

Figure 5 shows the SEM-images of the coated surfaces after coating with the nonfoamed and foam coatings. The non-foamed solutions covered the surface (Fig. 5A and $5 \mathrm{C}$ ), but the coating was uneven, and the coating may have penetrated into the substrate. The foam coating (Fig. 5B and 5D) seemed to close the surface more than the non-foamed solution, indicating that the coating penetrated less into the substrate and had a good filmforming ability. The EHEC-methyl nanocellulose foam appeared to have created a smoother surface, which could be due to the greater stability of these foams. 


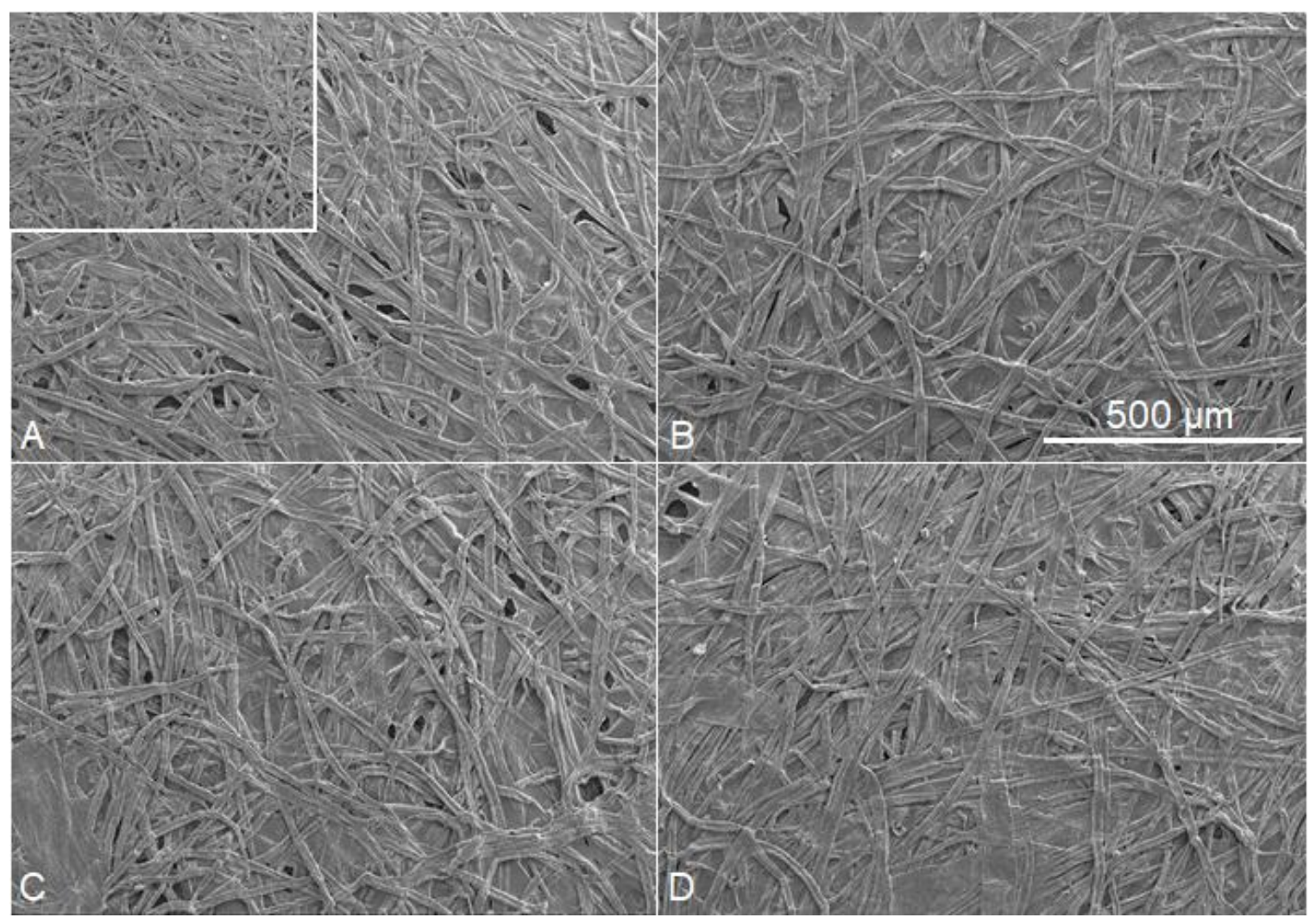

Fig. 5. Coated surfaces with non-foamed (A) methyl nanocellulose and (C) EHEC-methyl nanocellulose and with (B) methyl nanocellulose and (D) EHEC-methyl nanocellulose foams. The EHEC-methyl nanocellulose ratio was 50:50. The inset in image $A$ is an image of the uncoated substrate.

Selected foams were coated onto model substrates having different hydrophobicity and roughness levels. The foams were applied with a desktop rod coater and dried with hot air. Figure 6 shows the air permeance values and coat weights of the uncoated and coated samples, revealing the ability of the collapsed foam to close the surface of the substrate. Coating decreased the air permeance, especially on the smoother, hydrophobic substrate (Fig. 6B) when compared to the hydrophilic substrate (Fig. 6A). However, the coat weights were lower on the hydrophobic substrate, especially when the EHEC-MFC foams were used. The air permeance was reduced even at a low coat weight less than $2 \mathrm{~g} / \mathrm{m}^{2}$, but the bubble size in the foam, the particle size, and modification of MFC also influenced the coating uniformity and thus the air permeance (Kinnunen-Raudaskoski et al. 2014).

The air permeance values of the hydrophilic uncalendered and calendered substrates were $364 \mathrm{~mL} / \mathrm{min}$ and $226 \mathrm{~mL} / \mathrm{min}$, respectively. The air permeance was lower with three coating layers than with one coating layer, but with the $1 \mathrm{wt} \%$ EHEC-MFC coatings, the difference between once and thrice coated samples was not notable. The 3 wt\% EHEC-MFC and methyl nanocellulose coatings consisting of three layers had substantially lower air permeance values than samples with one coating layer, confirming a better holdout. In addition, calendering reduced the air permeance. The highest coat weight on the hydrophilic substrate was obtained with the foam generated from the $3 \mathrm{wt} \%$ EHEC-MFC solution. With the EHEC-MFC foams, a greater coat weight was achieved on the uncalendered substrate. A lower air permeance was obtained on the smoother substrate, 
probably because the coating was more uniform on the smooth surface. A similar effect was reported by Kumar et al. (2017b).

The air permeance values of the hydrophobic uncalendered and calendered substrates were $310 \mathrm{~mL} / \mathrm{min}$ and $198 \mathrm{~mL} / \mathrm{min}$, respectively (Fig. 6B), which was slightly lower than those of the hydrophilic substrates. A foam coating on the hydrophobic surface reduced the air permeance more after one coating layer than did the coating on the hydrophilic substrate. The differences between one and three coatings and different calendering levels were not as great as with coatings on the hydrophilic substrate. In addition, in the case of $1 \mathrm{wt} \%$ EHEC-MFC, only calendering affected the air permeance, which may be due to its tendency to form flocs, which may reduce the coating uniformity even if the substrate is coated three times.

The air permeance of the EHEC-MFC $3 \mathrm{wt} \%$ coating after three coating layers was lower on the hydrophobic substrate than on the hydrophilic substrate. The methyl nanocellulose coating reduced the air permeance to $1.2 \mathrm{~mL} / \mathrm{min}$ when the calendered substrate was coated three times, but for the methyl nanocellulose and $3 \mathrm{wt} \%$ EHEC-MFC coatings, neither the substrate nor calendering greatly affected the air permeance when the substrate was coated three times. Although the coat weight achieved with the methyl nanocellulose foam was lower than that with the EHEC-MFC foam generated from the 3 wt\% solution, the air permeance was notably lower. The stability of the EHEC-MFC foams was greater, and the bubble size was smaller, which should provide a more uniform coating, but it is possible that a greater coating uniformity was achieved with methyl nanocellulose due to its smaller particle size and better film-forming ability.
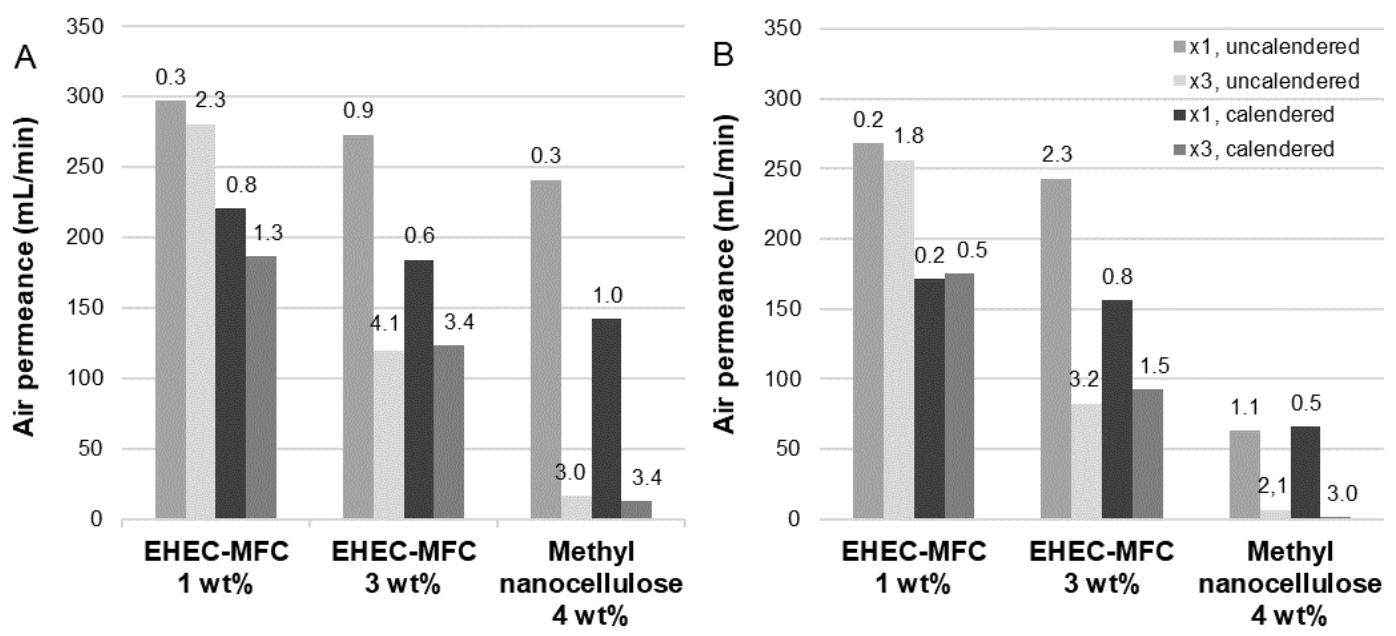

Fig. 6. Air permeance values of coated samples on (A) hydrophilic and (B) hydrophobic substrates. The air permeance values of the hydrophilic uncalendered and calendered substrates were $364 \mathrm{~mL} / \mathrm{min}$ and $226 \mathrm{~mL} / \mathrm{min}$, respectively, and those of the hydrophobic uncalendered and calendered substrates were $310 \mathrm{~mL} / \mathrm{min}$ and $198 \mathrm{~mL} / \mathrm{min}$, respectively. The number of coating layers is denoted as " $\mathrm{x} 1$ " or " $\mathrm{x} 3$ ". The coat weight $\left(\mathrm{g} / \mathrm{m}^{2}\right)$ for each coating is indicated above the air permeance value.

Figure 7 shows the SEM images of the samples with the EHEC-MFC and methyl nanocellulose foams coated on the calendered hydrophilic and hydrophobic substrates. The coat weight of the EHEC-MFC coating was $3.4 \mathrm{~g} / \mathrm{m}^{2}$ on the hydrophilic substrate after three coating layers and $1.5 \mathrm{~g} / \mathrm{m}^{2}$ on the hydrophobic substrate. The EHEC-MFC coating 
on the hydrophobic substrate seemed uneven, and the voids in the substrate were not fully covered, but the air permeance values were similar for both coatings (Fig. 6).

The coat weights for the methyl nanocellulose on the hydrophilic and hydrophobic substrates were $3.4 \mathrm{~g} / \mathrm{m}^{2}$ and $3.0 \mathrm{~g} / \mathrm{m}^{2}$, respectively. On both substrates the coating seemed to be even, and the surface was closed, but the coating seemed more uniform on the hydrophilic surface. After coating, the hydrophilic substrate showed wrinkling, probably due to the high wetting by the methyl nanocellulose foam. The hydrophilicity of the substrate may also enhance collapse of the foam and thus facilitate the wetting. In both cases, the air permeance was low, but it was lower on the hydrophobic substrate. The foam may have collapsed on the hydrophobic substrate due to the applied pressure during doctoring, and the methyl nanocellulose may have penetrated more into the substrate. The collapse of the foam under applied pressure may be more controlled, which could facilitate the formation of a uniform coating.

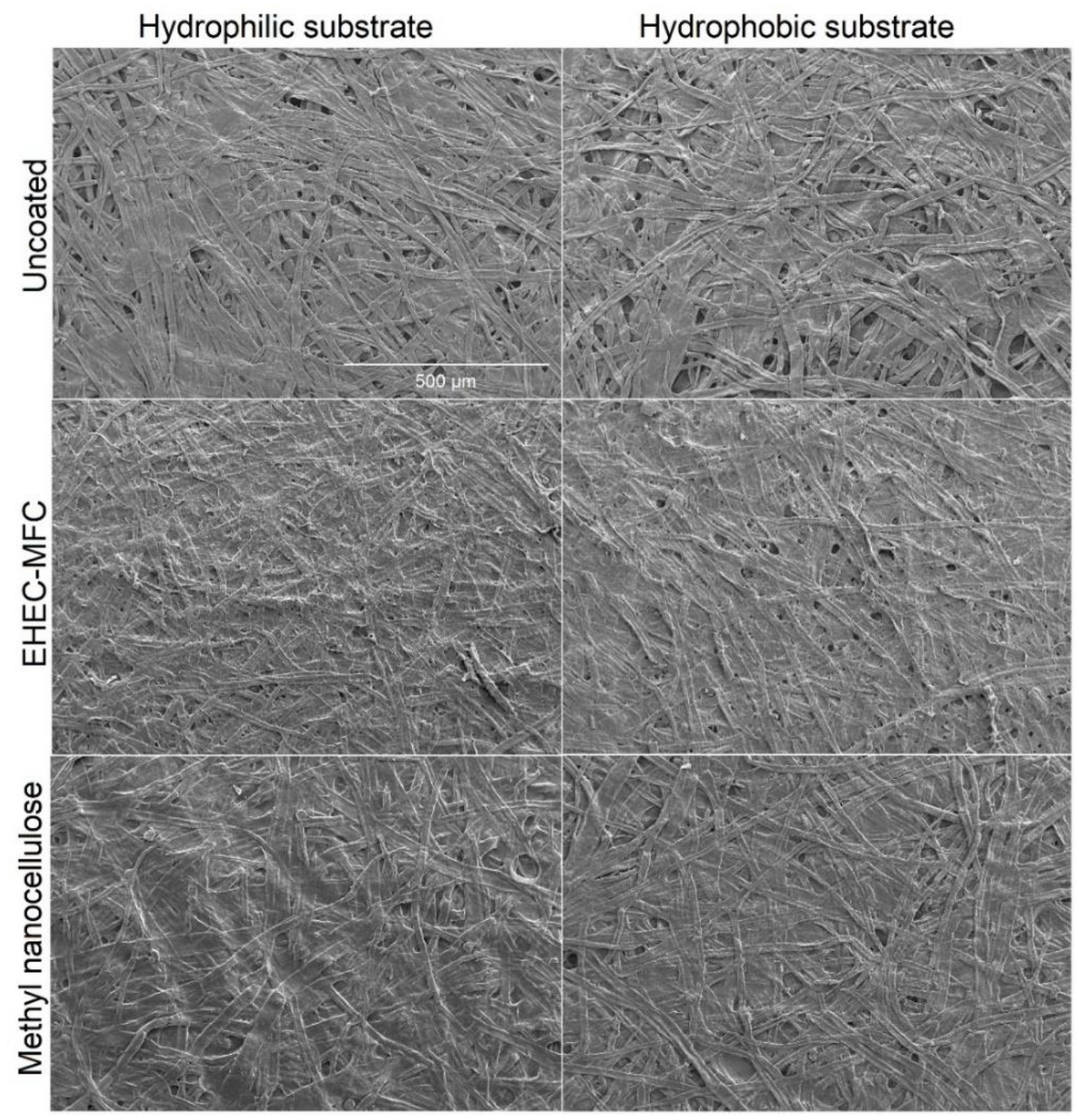

Fig. 7. Calendered hydrophilic and hydrophobic uncoated substrates and substrates coated with EHEC-MFC and with methyl nanocellulose, after three coating layers 
The SEM images also revealed bubbles and ruptures in the EHEC-MFC and methyl nanocellulose coatings (Fig. 8), presumably caused by the drying. Bubbles were observed in the methyl nanocellulose coating on the hydrophilic substrate, but the coating layer under the bubble was still uniform, and a multi-layer structure can thus be found beneficial for a grease barrier.

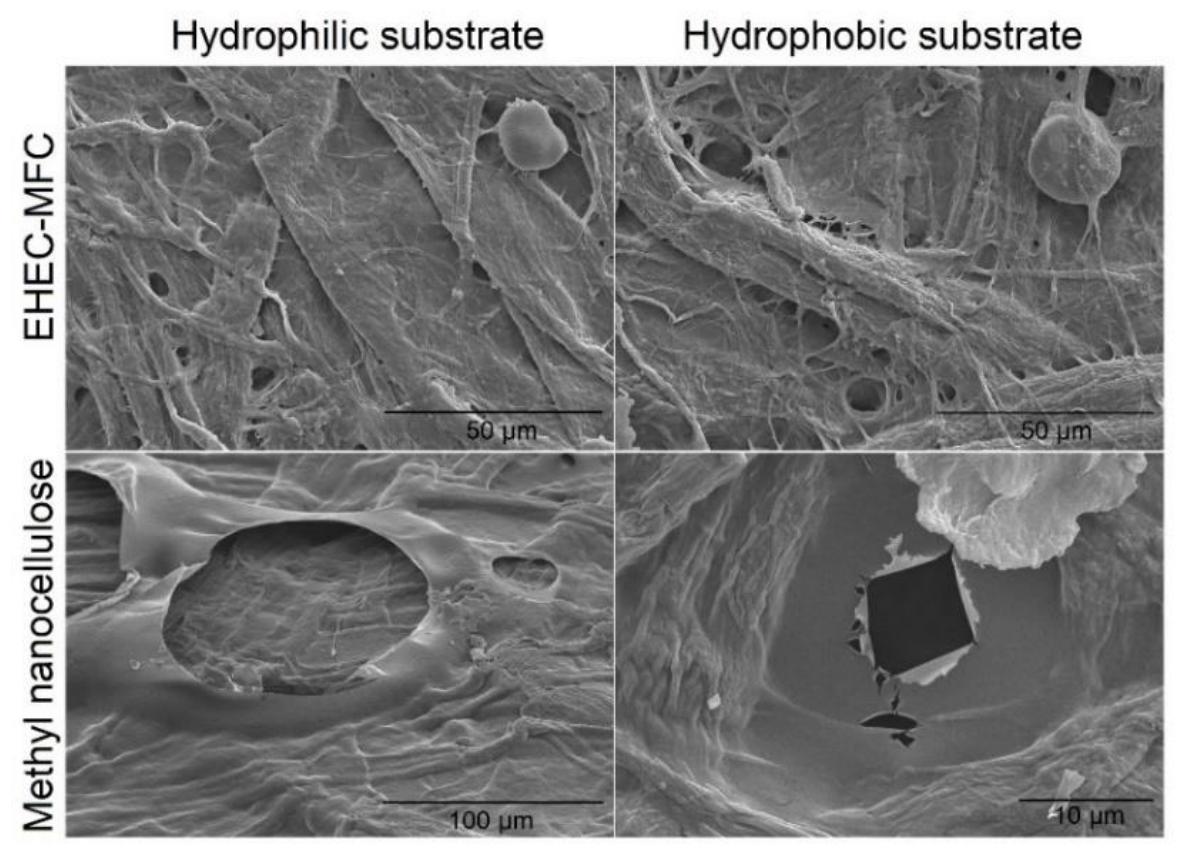

Fig. 8. SEM images of substrates coated with EHEC-MFC and with methyl nanocellulose

\section{Wetting and Barrier Properties of Coated Samples}

Contact angles were measured on the uncoated and coated samples using water and rapeseed oil. Figure 9 shows the values measured $1 \mathrm{~s}$ after placing the drop on the surface. The contact angle of oil was lowest and decreased more on the hydrophilic, calendered surface, compared to the other uncoated substrates (Fig. 9A). The contact angle of water was greatest on the hydrophobic surfaces, but water was absorbed completely into the surface on the hydrophilic, uncalendered surface after $1 \mathrm{~s}$ and absorbed within a few seconds on the hydrophilic, calendered surface (Fig. 9B).

The oil spread on and was absorbed by the EHEC-MFC-coated samples within $5 \mathrm{~s}$ (Fig. 9C). On the methyl nanocellulose coatings, the oil contact angle was greater, and the oil drop did not spread or become absorbed by the hydrophilic substrate (Fig. 9E), and calendering and the hydrophilicity of the substrate affected the spreading and absorption of the oil drop. The SEM images revealed that the film may be formed more on the surface of the hydrophilic substrate and that penetration into the substrate may be greater on the hydrophobic substrate. This result may also explain the lower contact angles of the oil on the methyl nanocellulose coating on the hydrophobic substrate.

On the hydrophilic substrate, the contact angle of water was notably greater on the EHEC-MFC and methyl nanocellulose coatings, although not as great on the methyl nanocellulose coating (Fig. 9D and 9F). This result may be due to the hydrophobicity of EHEC. The decrease in the contact angle of water with time was greater when the hydrophilic and calendered substrate was used. This result could be related to the MFC on the surface, which was observed in the SEM images (Fig. 7). The contact angles of water 
were lower on the coated hydrophobic surfaces than on the uncoated hydrophobic surfaces. These results may have been affected by the lower coat weight $\left(2.1 \mathrm{~g} / \mathrm{m}^{2}\right)$ of the methyl nanocellulose coating on the uncalendered hydrophobic substrate.
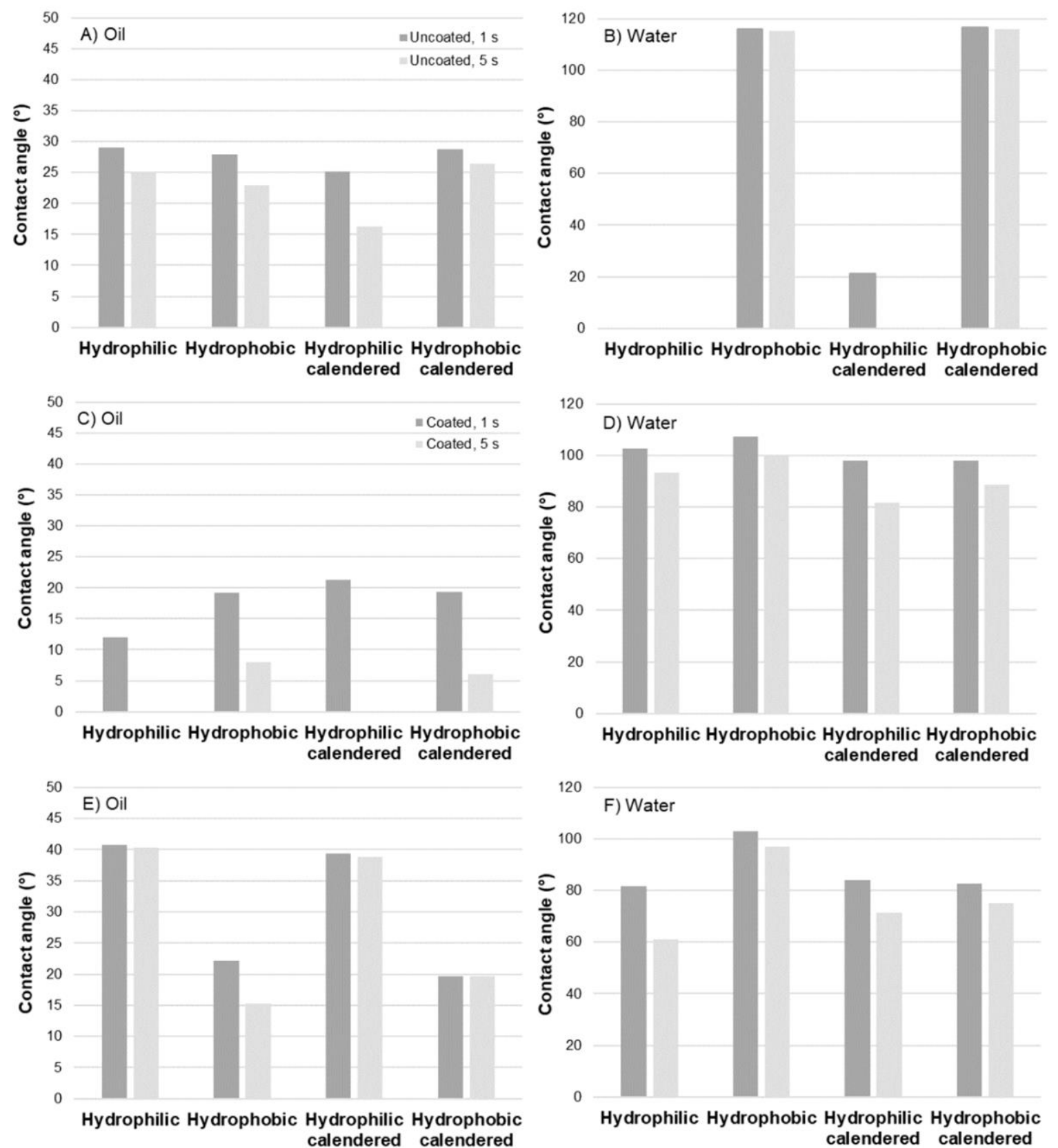

Fig. 9. Oil and water contact angles on (A and $B)$ uncoated substrates, $(C$ and $D)$ EHEC-MFC coatings, and ( $\mathrm{E}$ and $\mathrm{F}$ ) methyl nanocellulose coatings after $1 \mathrm{~s}$ and after $5 \mathrm{~s}$

Oil and grease resistance was measured in accordance with the ISO 16532-1 (2008) standard on the once and thrice coated hydrophilic and hydrophobic substrates. The oil penetrated through the EHEC-MFC samples immediately, due to the insufficient coverage, and the oil spread on the EHEC-MFC samples, presumably due to the presence of hydrophobically modified EHEC. On the methyl nanocellulose coating, the oil penetrated 
through pinholes, indicating that the coating was not uniform and that the coat weight was inadequate to provide barrier properties. Figure 10 shows the spreading of the rapeseed oil on the coated surfaces.

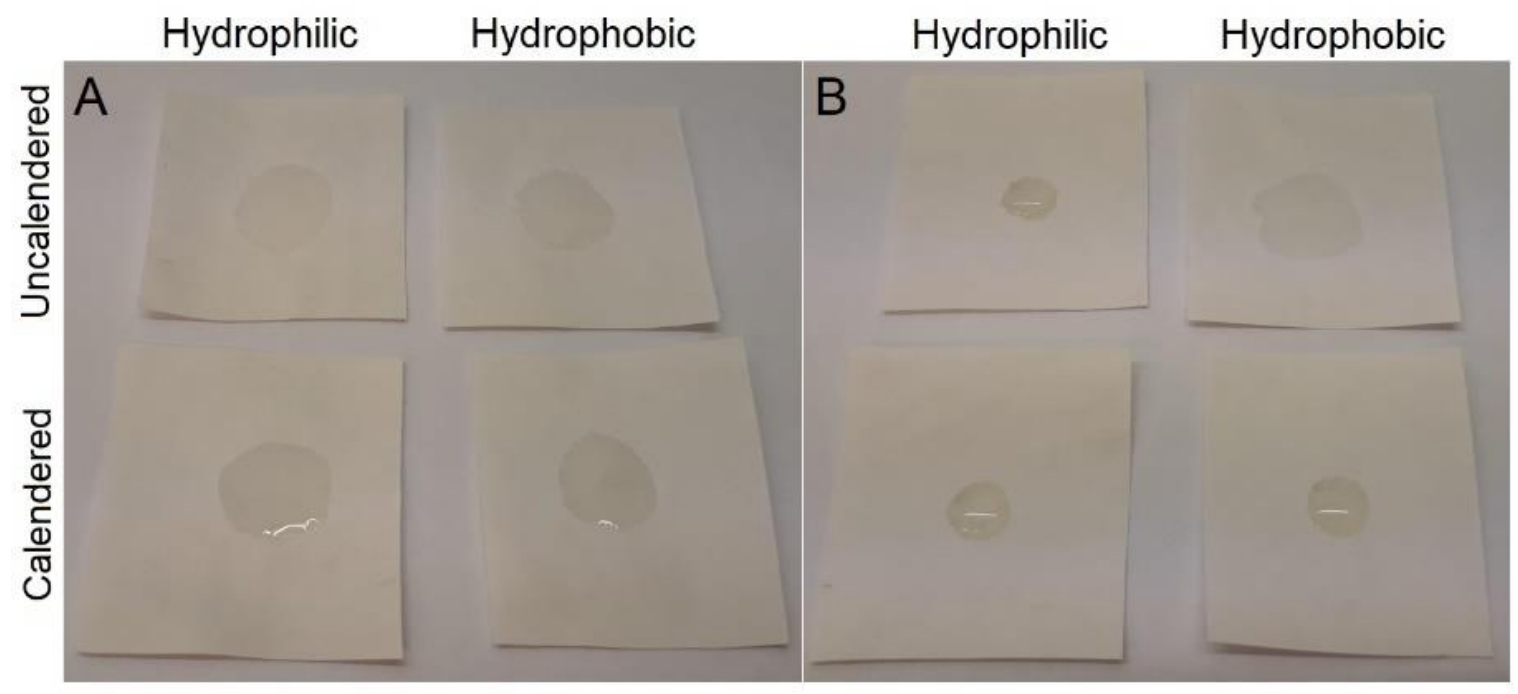

Fig. 10. Spreading of oil on (A) EHEC-MFC and (B) methyl nanocellulose coatings

\section{CONCLUSIONS}

1. Viscosity measurements indicated an interaction between the hydrophobically modified polymer and MFC and also changes in fibril orientation in the EHEC-MFC solution with increasing solid content.

2. The EHEC-MFC foams showed a greater stability, and EHEC could thus replace SDS and provide better foam stability and water retention, both of which are important in foam coatings.

3. Non-foamed solutions and foam coatings with methyl nanocellulose and EHEC solutions showed that the surface of the substrate could be efficiently closed.

4. Foam coatings on papers with different levels of roughness and hydrophobicity/ hydrophilicity confirmed that foam-substrate interaction had a great effect on coating quality.

5. The EHEC-MFC coating created a hydrophobic surface on a hydrophilic substrate, and methyl nanocellulose improved the oil resistance even at low coat weights.

\section{ACKNOWLEDGMENTS}

Stora Enso Oyj is thanked for financial support. Teija Laukala (M.Sc.) is thanked for the SEM images. Dr. Anthony Bristow is thanked for the linguistic revision of the manuscript. 


\section{REFERENCES CITED}

Arvidson, S. A., Lott, J. R., McAllister, J. W., Zhang, J., Bates, F. S., Lodge, T. P., Sammler, R. L., Li, Y., and Brackhagen, M. (2013). "Interplay of phase separation and thermoreversible gelation in aqueous methylcellulose solutions," Macromolecules 46(1), 300-309. DOI: 10.1021/ma3019359

Aulin, C., Gällstedt, M., and Lindström, T. (2010). "Oxygen and oil barrier properties of microfibrillated cellulose films and coatings," Cellulose 17, 559-574. DOI: 10.1007/s10570-009-9393-y

Bertsch, P., Diener, M., Adamcik, J., Scheuble, N., Geue, T., Mezzenga, R., and Fischer, P. (2018). "Adsorption and interfacial layer structure of unmodified nanocrystalline cellulose at air/water interfaces," Langmuir 34(50), 15195-15202. DOI: 10.1021/acs.langmuir.8b03056

Bertsch, P., Arcari, M., Geue, T., Mezzenga, R., Nyström, G., and Fischer, P. (2019). "Designing cellulose nanofibrils for stabilization of fluid interfaces," Biomacromolecules 20(12), 4574-4580. DOI: 10.1021/acs.biomac.9b01384

Cervin, N. T., Andersson, L., Ng, J. B. S., Olin, P., Bergström, L., and Wågberg, L. (2013). "Lightweight and strong cellulose materials made from aqueous foams stabilized by nanofibrillated cellulose," Biomacromolecules 14(2), 503-511. DOI: $10.1021 / \mathrm{bm} 301755 \mathrm{u}$

Cervin, N. T., Johansson, E., Benjamins, J.-W., and Wågberg, L. (2015). "Mechanisms behind the stabilizing action of cellulose nanofibrils in wet-stable cellulose foams," Biomacromolecules 16(3), 822-831. DOI: 10.1021/bm5017173

Cervin, N. T., Johansson, E., Larsson, P. A., and Wågberg, L. (2016). "Strong, waterdurable, and wet-resilient cellulose nanofibril-stabilized foams from oven drying," ACS Appl. Mater. Inter. 8(18), 11682-11689. DOI: 10.1021/acsami.6b00924

Desbrières, J., Hirrien, M., and Ross-Murphy, S. B. (2000). "Thermogelation of methylcellulose: Rheological considerations," Polymer 41(7), 2451-2461. DOI: 10.1016/S0032-3861(99)00413-9

Fairclough, J. P. A., Yu, H., Kelly, O., Ryan, A. J., Sammler, R. L., and Radler, M. (2012). "Interplay between gelation and phase separation in aqueous solutions of methylcellulose and hydroxypropylmethylcellulose," Langmuir 28(28), 10551-10557. DOI: $10.1021 / \mathrm{la} 300971 \mathrm{r}$

Fujisawa, S., Togawa, E., and Kuroda, K. (2017). "Nanocellulose-stabilized Pickering emulsions and their applications," Sci. Technol. Adv. Mat. 18(1), 959-971. DOI: 10.1080/14686996.2017.1401423

Gong, X., Wang, Y., and Chen, L. (2017). "Enhanced emulsifying properties of woodbased cellulose nanocrystals as Pickering emulsion stabilizer," Carbohyd. Polym. 169, 295-303. DOI: 10.1016/j.carbpol.2017.04.024

Hiltunen, S., Heiskanen, I., and Backfolk, K. (2018). "Effect of hydrothermal treatment of microfibrillated cellulose on rheological properties and formation of hydrolysis products," Cellulose 25(8), 4653-4662. DOI: 10.1007/s10570-018-1884-2

Hu, Z., Xu, R., Cranston, E. D., and Pelton, R. H. (2016). "Stable aqueous foams from cellulose nanocrystals and methyl cellulose," Biomacromolecules 17(12), 4095-4099. DOI: 10.1021/acs.biomac.6b01641

Hubbe, M. A., Ferrer, A., Tyagi, P., Yin, Y., Salas, C., Pal, L., and Rojas, O. J. (2017). "Nanocellulose in thin films, coatings, and plies for packaging applications: A review," BioResources 12(1), 2143-2233. DOI: 10.15376/biores.12.1.2143-2233 
Hunter, T. N., Pugh, R. J., Franks, G. V., and Jameson, G. J. (2008). "The role of particles in stabilising foams and emulsions," Adv. Colloid Interfac. 137(2), 57-81. DOI: $10.1016 /$ j.cis.2007.07.007

Iotti, M., Gregersen, Ø. W., Moe, S., and Lenes, M. (2011). "Rheological studies of microfibrillar cellulose water dispersions," J. Polym. Environ. 19, 137-145. DOI: 10.1007/s10924-010-0248-2

ISO 16532-1 (2008). "Paper and board - Determination of grease resistance - Part 1: Permeability test," International Organization for Standardization, Geneva, Switzerland.

Karppinen, A., Saarinen, T., Salmela, J., Laukkanen, A., Nuopponen, M., and Seppälä, J. (2012). "Flocculation of microfibrillated cellulose in shear flow," Cellulose 19, 18071819. DOI: $10.1007 / \mathrm{s} 10570-012-9766-5$

Kenttä, E., Kinnunen-Raudaskoski, K., and Hjelt, T. (2014). "Characterization of thin pigment coating layers produced by foam coating," TAPPI J. 13(7), 21-27.

Kenttä, E., Koskela, H., Paunonen, S., Kinnunen-Raudaskoski, K., and Hjelt, T. (2016). "Functional surfaces produced by foam coating," TAPPI J. 15(8), 515-521. DOI: 10.32964/TJ15.8.515

Kinnunen-Raudaskoski, K., Hjelt, T., Forsström, U., Sadocco, P., and Paltakari, J. (2017). "Novel thin functional coatings for paper by foam coating," TAPPI J. 16(4), 179-186. DOI: $10.32964 / \mathrm{TJ} 16.4 .179$

Kinnunen-Raudaskoski, K., Hjelt, T., Kenttä, E., and Forsström, U. (2014). “Thin coatings for paper by foam coating," TAPPI J. 13(7), 9-19. DOI: 10.32964/TJ13.7.9

Kumar, V., Elfving, A., Koivula, H., Bousfield, D., and Toivakka, M. (2016). "Roll-toroll processed cellulose nanofiber coatings," Ind. Eng. Chem. Res. 55(12), 3603-3613. DOI: 10.1021/acs.iecr.6b00417

Kumar, V., Koppolu, V. R., Bousfield, D., and Toivakka, M. (2017b). "Substrate role in coating of microfibrillated cellulose suspensions," Cellulose 24(3), 1247-1260. DOI: 10.1007/s10570-017-1201-5

Kumar, V., Ottesen, V., Syverud, K., Gregersen, Ø. W., and Toivakka, M. (2017a). "Coatability of cellulose nanofibril suspensions: Role of rheology and water retention," BioResources 12(4), 7656-7679. DOI: 10.15376/biores.12.4.7656-7679

Lam, S., Velikov, K. P., and Velev, O. D. (2014). "Pickering stabilization of foams and emulsions with particles of biological origin," Curr. Opin. Colloid In. 19(5), 490-500. DOI: 10.1016/j.cocis.2014.07.003

Lappalainen, T., Salminen, K., Kinnunen, K., Järvinen, M., Mira, I., and Andersson, M. (2014). "Foam forming revisited. Part II. Effect of surfactant on the properties of foam-formed paper products," Nord. Pulp Pap. Res. J. 29(4), 689-699. DOI: 10.3183/npprj-2014-29-04-p689-699

Lavoine, N., Bras, J., and Desloges, I. (2014). "Mechanical and barrier properties of cardboard and 3D packaging coated with microfibrillated cellulose," J. Appl. Polym. Sci. 131(8). DOI: 10.1002/app.40106

Li, J., Yang, X., Xiu, H., Dong, H., Song, T., Ma, F., Feng, P., Zhang, X., Kozliak, E., and Ji, Y. (2019). "Structure and performance of plant fiber based foam material by fibrillation via refining treatment," Ind. Crop. Prod. 128, 186-193. DOI: 10.1016/j.indcrop.2018.10.085

Liu, Y., Kong, S., Xiao, H., Bai, C. Y., Lu, P., and Wang, S. F. (2018). “Comparative study of ultra-lightweight pulp foams obtained from various fibers and reinforced by MFC," Carbohyd. Polym. 182, 92-97. DOI: 10.1016/j.carbpol.2017.10.078 
Lyytikäinen, J., Morits, M., Österberg, M., Heiskanen, I., and Backfolk., K. (2020). "Skin and bubble formation in films made of methyl nanocellulose, hydrophobically modified ethyl(hydroxyethyl)cellulose and microfibrillated cellulose," Cellulose. DOI: $10.1007 / \mathrm{s} 10570-020-03557-0$

Miller, K. S., and Krochta, J. M. (1997). "Oxygen and aroma barrier properties of edible films: A review," Trends Food Sci. Tech. 8(7), 228-237. DOI: 10.1016/S09242244(97)01051-0

Ortega-Toro, R., Jiménez, A., Talens, P., and Chiralt, A. (2014). "Effect of the incorporation of surfactants on the physical properties of corn starch films," Food Hydrocolloid. 38, 66-75. DOI: 10.1016/j.foodhyd.2013.11.011

Poptoshev, E., Um, S.-U., and Pugh, R. J. (1997). "Influence of surface aging on the drainage of foam films stabilized by aqueous solutions of ethyl hydroxyethyl cellulose," Langmuir 13(15), 3905-3908. DOI: 10.1021/la970292q

SCAN-P 85:02 (2002). “Air permeance," Scandinavian Pulp, Paper and Board Testing Committee, Stockholm, Sweden.

Thuresson, K., and Lindman, B. (1997). "Effect of hydrophobic modification of a nonionic cellulose derivative on the interaction with surfactants. Phase behavior and association," J. Phys. Chem. B 101(33), 6460-6468. DOI: 10.1021/jp9702053

Villalobos-Carvajal, R., Hernández-Muñoz, P., Albors, A., and Chiralt, A. (2009). "Barrier and optical properties of edible hydroxypropyl methylcellulose coatings containing surfactants applied to fresh cut carrot slices," Food Hydrocolloid. 23(2), 526-535. DOI: 10.1016/j.foodhyd.2008.02.008

Villalobos, R., Hernández-Muñoz, P., and Chiralt, A. (2006). "Effect of surfactants on water sorption and barrier properties of hydroxypropyl methylcellulose films," Food Hydrocolloid. 20(4), 502-509. DOI: 10.1016/j.foodhyd.2005.04.006

Wemmer, J., Gossweiler, E., Fischer, P., and Windhab, E. J. (2019). "Effect of foaming on mechanical properties of microfibrillated cellulose-based porous solids," Cellulose 26, 2487-2497. DOI: 10.1007/s10570-018-02228-5

Xhanari, K., Syverud, K., Chinga-Carrasco, G., Paso, K., and Stenius, P. (2011). "Reduction of water wettability of nanofibrillated cellulose by adsorption of cationic surfactants," Cellulose 18, 257-270. DOI: 10.1007/s10570-010-9482-y

Xiang, W., Preisig, N., Ketola, A., Tardy, B. L., Bai, L., Ketoja, J. A., Stubenrauch, C., and Rojas, O. J. (2019). "How cellulose nanofibrils affect bulk, surface, and foam properties of anionic surfactant solutions," Biomacromolecules 20(12), 4361-4369. DOI: 10.1021/acs.biomac.9b01037

Yook, S., Park, H., Park, H., Lee, S.-Y., Kwon, J., and Youn, H. J. (2020). “Barrier coatings with various types of cellulose nanofibrils and their barrier properties," Cellulose 27, 4509-4523. DOI: 10.1007/s10570-020-03061-5

Article submitted: September 3, 2020; Peer review completed: November 15, 2020; Revised version received and accepted: November 23, 2020; Published: November 25, 2020.

DOI: 10.15376/biores.16.1.597-613 